\title{
Efeitos do real: realidade e escritura em Roland Barthes
}

\author{
Pedro Henrique Couto Torres
}

RESUMO: 0 presente trabalho pretende debater a produção ensaística de Roland Barthes na década de 1960. 0 argumento analítico será postulado desde "L'effet de réel", de 1968, buscando um desenvolvimento crítico a partir da noção de particularidade e detalhe concreto. 0 percurso das teorias realistas novecentistas será considerado a partir do emblemático texto de Phillipe Sollers "Le roman et l'expérience des limites", de 1965, no qual o realismo é entendido como um prejuízo a partir do qual o gesto escritural deva exprimir algo extrínseco, uma realidade fora do texto. A realidade, tal como assumida neste trabalho, será problematizada como uma instância textual que polemiza a referencialidade e os projetos miméticos de transposição do real. PALAVRAS-CHAVE: Efeito de real; Roland Barthes; Detalhe concreto; Realismo; Representação.

\section{Reality effects: reality and writing in Roland Barthes}

ABSTRACT: The present paper aims to discuss Roland Barthes' essayistic production during the 1960 decade. The analytical argument is developed from "The reality effect", a 1968 Barthes' essay, passing through the critical notion of particularity and concrete detail. The background concerns the realistic theories from the nineteenth century presented in the emblematic 1965 text, "Le roman et l'expérience des limites", by Phillipe Sollers, in which the realism is comprehended as a loss suffered by the writing gesture for it represents something external of the text itself. Reality, as regarded in this paper, is questioned and posed as a textual instance that tackles the problematics of reference and of the mimetic projects of the reality transposition. KEYWORDS: Reality effect; Roland Barthes; Concrete Detail; Realism; Representation.

Do real, não da realidade, deriva um efeito de ilusão. Essa é a premissa do ensaio de Roland Barthes, publicado originalmente na Communications nć 11, cuja preocupação focava as discussões da verossimilhança desde sua herança retórica e seus fundamentos de gênero e opinião pública. "Propõe-se mostrar" diz Todorov, o prefaciador da revista, "que os discursos não são regidos por uma correspondência a seus referentes, mas por suas leis próprias" (TODOROV, 1968, p. 1-2). Ou, sinteticamente: "Trata-se de deslocar a linguagem de sua transparência ilusória, de aprender a percebê-la e, ao mesmo tempo, estudar as técnicas de que ela se serve, para não existir diante de nossos olhos." (TODOROV, 1968, p. 2).

A linguagem, segundo tais objetivos, se colocaria em um circuito de invisibilidade, ocultando seus desígnios, dissimulando uma referência à exterioridade. Ela, em última instância, ocultaria sua estrutura, muito embora, não a pudesse anular. Numa aberta interlocução de gênese de sentido até uma rede esboçada na causalidade, a linguagem,tentaria, mediante palavras, dizer o mundo. Busca-se, portanto, menos a verdade do que sua impressão: concorrem o mundo, que é visível, e a linguagem, que é invisível.

A pesquisa semiológica, contudo, no afã disciplinar que the guiava as direções, pretendia um cálculo sintético que resolvesse as contradições frente às quais se colocava e, numa perquirição totalizante e simultânea, indicasse a relação de causa-efeito de sua suposta distribuição. Resultava, ora numa justificativa, ora numa lógica estrutural de mecanismos e dispositivos verbais: o seu imperativo era afastar-se de uma tentativa de teorização mimética, para enfim, salvar-se sob a tutela da anotação semiótica.As intenções, tão boas em sua origem, não deslembrariam o projeto autoritário e violento da disciplina, da ciência, enfim, da construção daquele edifício labiríntico e solene: a Semiologia.

Em busca de interpretações calcadas na autorreferência, as denúncias se asseveravam. Philippe Sollers, em 1965 criticava 0:

\footnotetext{
${ }^{1}$ Doutorando em Literatura pela Universidade de Brasília. Mestre em Literatura e graduado em Letras pela mesma instituição. E-mail para contato: couto.pedroh@yahoo.com.br.
} 
pretenso realismo (...), esse preconceito que consiste em acreditar que uma escritura deva exprimir alguma coisa que não é dada nesta escritura, alguma coisa sobre a qual a unanimidade pode se fazer imediatamente. Mas é preciso ver que essa concordância só pode se dar sobre convenções prévias, sendo a própria noção de realidade uma convenção e um conformismo, uma espécie de contrato tácito entre o indivíduo e seu grupo social. (SOLLERS, apud COMPAGNON, 1999, p. 97).

A escritura apareceria, pois, como uma resposta a certo entendimento mimético da realidade (ou do real). Menos radical é a "verdade" ficcional pautada mimeticamente do que aquela que, apesar dos dados externos, constitui-se em um desafio textual de coerência. A "verdade" do texto não é aquela pretensamente transposta do nosso mundo tangível, mas aquela que, segundo certas normas, configuraria uma realidade crível. Daí que há de se pensar se a Literatura dialoga, não com a Verdade, essa com letra capital, mas com suas deformações, com suas formas alternativas, com seus recuos reticentes.

Em 1968, Barthes talvez sob o efeito da leitura de Sollers, dedicaria um texto à reflexão dos problemas de realismo e realidade via literatura. Sua argumentação consistia na compreensão do significado e da significação do insignificante. 0 verossímil era perquirido através de uma conta na qual agregavam-se detalhes desprovidos de aparente relevância que, apesar disso, entrariam na estimativa textual.É pois que a estrutura-assim lembra Barthes - recuperaria os detalhes supérfluos, os enchimentos, os remplissages.

Esses detalhes, aparentemente desconexos, permitiriam uma outra ideia da referência, a semiosis. 0 piano que Barthes resgata em Flaubert, escritor de que se ocupa juntamente com Michelet, estaria ligado à atmosfera burguesa, essa constante da ordem do visível e do notável. Quanto ao barômetro, o detalhe irrelevante, escreve Barthes:

\begin{abstract}
Parece, entretanto que, se a análise se pretende exaustiva (e que valor poderia ter um método que não considerasse a integralidade de seu objeto, isto é, no caso, toda a superfície do tecido narrativo?), procurando atingir, para assinalar-Ihe um lugar na estrutura, o detalhe absoluto, a unidade indivisível, a transição fugitiva, deve fatalmente encontrar notações que nenhuma função (mesmo a mais indireta) permite justificar: essas notações são escandalosas (do ponto de vista da estrutura), ou o que é mais ainda inquietante, parecem harmonizadas a uma espécie de luxo da narração, pródiga a ponto de despender detalhes "inúteis" e elevar aqui e ali o custo da informação narrativa. Pois, se na descrição de Flaubert é, com todo o rigor, possível ver na notação do piano um índice do standing burguês de sua proprietária, e na dos cartões um signo de desordem e como que de privação de numa herança, destinados a conotar a atmosfera da casa de Aubain, nenhuma finalidade parece justificar a referência ao barômetro, objeto que não é incongruente nem significante e não participa, à primeira vista, da ordem do notável; e na frase de Michelet, mesma dificuldade em perceber estruturalmente todos os detalhes (...) Mesmo não sendo numerosos os "detalhes inúteis" parecem, portanto, inevitáveis: todo discurso narrativo ocidental do tipo corrente possui alguns." (BARTHES, 1971, p. 36).
\end{abstract}

0 escândalo da lista minuciosa, que inventaria superficialmente a estrutura narrativa, parece fazer conexão inevitável ao modo de narrar operado pelo escritor ocidental, tentado a compor uma hipotipose. A lista, quando contida no texto, remete a uma certa concepção de objetividade, cerne das suposições do realismo, que deveria em cores vivas, confundir a coisa, em denotação, com a representação da coisa. Essa seria a visão que, repleta de prejuízos, não consideraria a força desconcertante da palavra que, invariavelmente, retornaria, sempre, a outra palavra. Contra os clichês de um entendimento simplificador da mimesis, Barthes mencionaria o detalhe concreto:

Semioticamente, o "detalhe concreto" é constituído da colusão direta de um referente e de um significante; o significado é expulso do signo, e com ele, bem entendido, a possibilidade de desenvolver uma forma do significado, isto é, na realidade, a própria estrutura narrativa (a literatura realista é, certamente, 
narrativa, mas o é porque nela o realismo é somente parcelar, errático, confinado aos "detalhes" e porque o discurso narrativo mais realista que se possa imaginar se desenvolve de acordo com os caminhos irrealistas), isto é o que se poderia chamar de ilusão referencial. A verdade desta ilusão é a seguinte: suprimido da enunciação realista, a título de significação de conotação; pois no mesmo instante em que esses detalhes são supostos denotarem diretamente o real, eles não fazem mais que os significarem, sem dizê-lo: o barômetro de Flaubert, a pequena porta de Michelet, não dizem nada mais que isto: somos o real; é a categoria do "real" (e não seus conteúdos contingentes) que é então significada; ou melhor, a própria carência do significado em proveito do único referente torna-se 0 próprio significante do realismo: produz-se um efeito de real, fundamento desse inverossímil inconfessado que forma a estética de todas as obras correntes da modernidade. (BARTHES, 1971, p. 43).

Não há significado. Há, tão-somente, a forma do significado. 0 barômetro que Flaubert insere em seu conto é a palavra barômetro, alusivamente colocada como referência, não a um certo objeto empírico do mundo extraliterário, mas como encadeamento de outros itens discursivos, em suma, de outras palavras do texto. Flaubert, na esteira do efeito de real, se colocaria na modernidade, onde a secularidade da representação mimética estiolaria. Prossegue Barthes:

Esse novo verossímil é muito diferente do antigo, pois não é nem o respeito às leis do "gênero", nem mesmo sua máscara, mas provém da intenção de alterar a natureza tripartida do signo, para fazer da notação o puro encontro de um objeto e de sua expressão. A desintegração do signo - que parece muito bem ser o grande caso da modernidade - está certamente presente na empresa realista, mas de uma forma regressiva de algum modo, uma vez que se faz em nome de uma plenitude referencial, quando hoje, ao contrário, se trata de esvaziar o signo e de recuar infinitamente seu objeto até colocar em discussão, de maneira radical, a estética secular da "representação". (BARTHES, 1971, p. 44).

Numa opção crítica, Roland Barthes comporia a cena da semiologia francesa numa tensão contrária às tradições explicativas e históricas da literatura. 0 texto "L'effet de réel" de 1968, deslindaria um projeto urgente que, entretanto, seria fragmentado e reavaliado anos depois. Na Aula, Barthes, para além de um purismo opositor de escritura e literatura, empreenderia uma deflagração das intuições que sempre o acompanharam em sua trajetória de pensamento. É a literatura, que na hipótese possível da extinção epistêmica, se guardaria necessariamente, em seu saber. Barthes afirma:

A literatura assume muitos saberes. (...). Se, por não sei que excesso de socialismo ou de barbárie, todas as nossas disciplinas devessem ser expulsas do ensino, exceto numa, é a disciplina literária que devia ser salva, pois todas as ciências estão presentes no monumento literário. É nesse sentido que se pode dizer que a literatura, quaisquer que sejam as escolas em nome das quais ela se declara, é absolutamente, categoricamente realista: ela é a realidade, isto é, o próprio fulgor do real. (BARTHES, 1980, p. 17-18)

0 autor também se reconciliaria (se é que seja essa a palavra apropriada) com a representação, numa contradição entre a apresentação e a impossibilidade da imitação, a energia do desejo presente na criação e na vida:

A segunda força da literatura, é sua força de representação. Desde os tempos antigos até as tentativas de vanguarda, a literatura se afaina na representação de alguma coisa. 0 quê? Direi brutalmente: o real. 0 real não é representável, e é porque os homens querem constantemente representá-lo por palavras que há uma história da literatura. Que o real não seja representável - mas somente demonstrável - pode ser dito de vários modos: quer o definamos, com Lacan, como o impossível, o que não pode ser atingido e escapa ao discurso, quer se verifique, em termos topológicos, que não se pode fazer coincidir uma ordem pluridimensional (o real) e uma ordem 
unidimensional (a linguagem). Ora, é precisamente a essa impossibilidade topológica que a literatura não quer, nunca quer render-se. Que não haja paralelismo entre 0 real e a linguagem, com isso os homens se conformam, e é essa recusa, talvez tão velha quanto a própria linguagem, que produz, numa faina incessante, a literatura. (BARTHES, 1980, p. 22-23).

Há, portanto, em Barthes, um caminho de revisão crítica, multifacetada. Daí que toda sua obra preliminar, positiva, decorrerá numa negatividade ativa, em que o apofatismo deflagra outras intuições e direções. A positividade semiológica seria enfrentada na dissolução de categorias rígidas de compreensão e de lógicas puramente explicadoras. A disciplina, a ciência, esfacelam-se:

(...) a semiologia não é uma chave, ela não permite apreender diretamente o real, impondo-lhe um transparente geral que o tornaria inteligível; o real, ela busca antes, soerguê-lo, em certos pontos e em certos momentos, e ela diz que esses efeitos de solevamento do real são possíveis sem chave: aliás é precisamente quando a semiologia quer uma chave que ela não desvenda coisa alguma. (BARTHES, 1980, p. 37-38).

No absurdo de representar o irrepresentável, o pensamento de Barthes, para além de qualquer rótulo, abala a caução do pensamento seguro e disciplinado, que se convence de seu poder e violência. 0 pensamento de Roland Barthes, entre a gentileza e 0 amor, adere cada vez mais ao real, situando-nos sempre frente à impossibilidade de a literatura diminuir a vida.

\section{REFERÊNCIAS}

BARTHES, R. Efeito de real. In: Vários autores. Literatura e semiologia. Petrópolis: Vozes, 1971. Aula. 14. ed. Tradução de Leyla Perrone-Moisés. São Paulo: Editora Cultrix, 1980.

COMPAGNON, Antoine. o demônio da teoria: literatura e senso comum. Tradução de Cleonice Paes Barreto Mourão. Belo Horizonte: Ed. UFMG, 1999.

TODOROV,T. Introduction. In: Communications, 11. Recherches sémiologiques le vraisemblable. 1968. Disponível em: http://www.persee.fr/web/revues/home/prescript/issue/comm_05888018_1968_num_11_1. Acesso em: 20/05/2015. 